
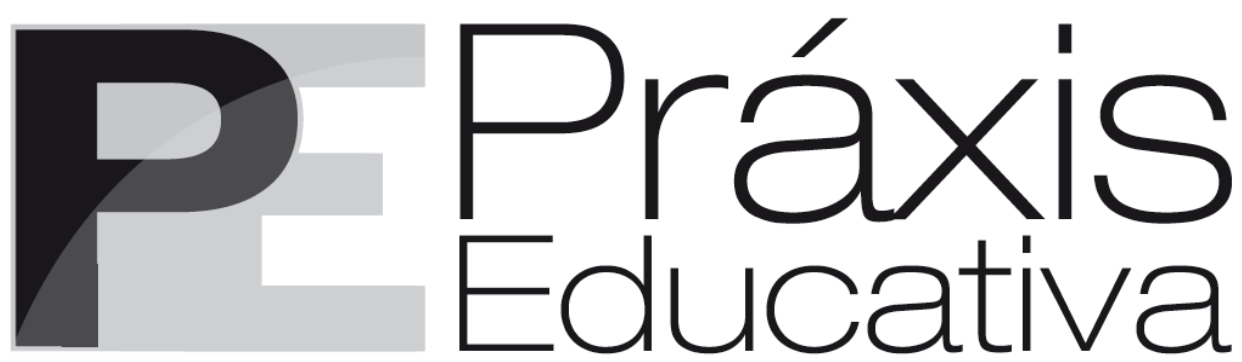

ISSN 1809-4309 (Versão online) DOI: 10.5212/PraxEduc.v.11i3.0008

\title{
Os sentidos do SARESP para professores e alunos da rede pública estadual paulista e a gestão do currículo na sala de aula
}

\author{
The meanings of SARESP for teachers and students from São Paulo's public \\ school system and the management of the curriculum inside the classroom
}

\section{Los sentidos del SARESP para profesores y alumnos de la red pública estatal paulista y la gestión del programa en la sala de clases}

\author{
Renata Cristina Oliveira Barrichelo Cunha* \\ Andreza Barbosa ${ }^{* *}$ \\ Natiely Pasetto e Silva** \\ Daniela Aparecida Lando ${ }^{* * * *}$
}

Resumo: $\mathrm{O}$ artigo discute os efeitos das avaliações externas na gestão do currículo na sala de aula. O objetivo da pesquisa desenvolvida foi compreender quais sentidos são produzidos por professores e alunos frente às exigências do SARESP. O trabalho de campo envolveu o acompanhamento de atividades de trabalho pedagógico coletivo de uma escola pública do interior paulista durante os anos de 2014 e 2015 . A análise dos registros dos encontros que discutiram a relação entre avaliação e currículo permite afirmar que o SARESP pode ser considerado como parâmetro e referência para a reflexão e ajustes no planejamento dos professores, mas a centralidade que assumiu na organização do trabalho pedagógico está caracterizada como medida e controle, ao definir o que ensinar e como avaliar o trabalho do professor e do aluno, esvaziando a discussão sobre o projeto político-pedagógico.

Palavras-chave: Avaliação. Currículo. Cotidiano escolar.

Abstract: This article discusses the effects of the external evaluations on the curriculum management inside the classroom. The purpose of this research was to comprehend which meanings are produced by teachers

\footnotetext{
* Professora do Programa de Pós-Graduação em Educação da Universidade Metodista de Piracicaba (UNIMEP). E-mail: <renata_bcunha@yahoo.com.br>.

** Professora do Programa de Pós-Graduação em Educação da Universidade Metodista de Piracicaba (UNIMEP). Email:<andrezab27@gmail.com>.

*** Graduanda em Psicologia na Universidade Metodista de Piracicaba (UNIMEP). Bolsista de Iniciação Científica PIBIC/CNPq (2014-2015 e 2015-2016).E-mail: <ntpsilva@unimep.br>.

**** Graduanda em Letras-Inglês na Universidade Metodista de Piracicaba (UNIMEP). Foi bolsista de Iniciação Científica - PIBIC/CNPq (2014-2015).E-mail: <dalando@unimep.br>.
}

Práxis Educativa, Ponta Grossa, p. 657-675, v. 11, n. 3, set./dez. 2016 Disponível em: < http://www.revistas2.uepg.br/index.php/praxiseducativa > 
faced by the requirements of SARESP. The fieldwork involved the accompaniment of collective pedagogical work activities of a public school in São Paulo state countryside between the years 2014 and 2015. The analysis of the meeting recordings that discussed the relationship between evaluation and curriculum allows us to state that SARESP can be considered as a parameter and reference for reflection and adjustments in the teacher's planning methods, but the centrality that it has assumed in the organization of the pedagogical work is characterized as a measure and control, when defining what to teach and how to evaluate the work of the teacher and the student, emptying the discussion about the political-pedagogical project of the school.

Keywords: Evaluation. Curriculum. School routine.

Resumen: El artículo discute los efectos de las evaluaciones en la gestión del programa en la sala de clases. El objetivo de la investigación fue comprender cuales sentidos son producidos por profesores y alumnos delante de las exigencias del SARESP. El trabajo de campo acompañó las actividades de trabajo pedagógico colectivo de una escuela pública del interior del estado de São Paulo durante los años de 2014 y 2015. El análisis de registros de los encuentros que discutían la relación entre evaluación y programa permite afirmar que el SARESP puede ser considerado como parámetro de referencia para reflexión y ajustes en el planeamiento de los profesores, pero la centralidad que ha asumido en la organización del trabajo pedagógico está caracterizada como medida y control, al definir lo que enseñar y como evaluar el trabajo del profesor y del alumno, agotando la decisión sobre el proyecto político-pedagógico de la escuela.

Palabras-clave: Evaluación. Programa. Cotidiano escolar.

\section{Introdução}

Desde o final da década de 1990, a discussão sobre a avaliação dos sistemas educacionais vem crescendo e, de acordo com Bauer (2014) é, sobretudo, a partir de 2010 que o interesse pelas relações entre avaliação e gestão aumentou significativamente. No entanto, segundo a autora, ainda são necessárias investigações que problematizem a utilização dos resultados das avaliações e os currículos praticados nas escolas e nos sistemas.

As reflexões e discussões propostas neste artigo foram construídas ao longo de um projeto de pesquisa financiado pelo CNPq/CAPES (2013-2015), que objetivou compreender a organização do trabalho pedagógico no contexto da rede pública paulista e analisar as determinações, tensões e resistências em relação às avaliações em larga escala e ao currículo oficial ${ }^{1}$. Os resultados aqui apresentados focalizam a relação entre o Sistema de Avaliação de Rendimento Escolar do Estado de São Paulo (SARESP) e a gestão do currículo na sala de aula, a partir do olhar de professores e alunos do Ensino Fundamental II e Médio.

O trabalho de campo envolveu o acompanhamento das Aulas de Trabalho Pedagógico Coletivo (ATPC) de uma escola pública paulista do interior durante os anos de 2014 e 2015. Esses encontros contaram com a participação dos gestores e professores, mas de alguns deles participaram alunos convidados a discutir temáticas específicas, como o SARESP.

A articulação dos pontos de vista de alunos e professores acerca do SARESP pode contribuir com a discussão sobre as implicações das avaliações externas no cotidiano da sala de aula, e sobre seus efeitos na organização do trabalho pedagógico e gestão do currículo. Isso porque o trabalho na sala de aula é atravessado por múltiplas expectativas e as escolhas do que, como e por que ensinar

${ }^{1}$ O projeto foi aprovado pelo Comitê de Ética da Universidade (Protocolo n. 75/13).

Práxis Educativa, Ponta Grossa, p. 657-675, v. 11, n. 3, set./dez. 2016 Disponível em: <http://www.revistas2.uepg.br/index.php/praxiseducativa> 
carregam não só as marcas da formação docente e da proposta pedagógica da escola, mas da política educacional.

A escolha por discutir o SARESP, a partir dos sentidos produzidos pelos professores e alunos, parte dos princípios de que o homem tem necessidade de "dar um sentido à vida ou construir uma vida cheia de sentido" (NAMURA, 2004, p. 91), e que a natureza especificamente humana é marcada pela sua capacidade de criar e atribuir sentidos de acordo com suas experiências e condições de existência.

\section{As avaliações em larga escala: dos motivos aos efeitos}

O aumento do interesse pela avaliação do desempenho dos alunos, de acordo com Horta Neto (2010), corresponde ao aumento da demanda por educação nos países centrais, e a preocupação com o conteúdo aprendido/ensinado na escola e o considerado necessário para a vida social.

Nesse contexto, as avaliações em larga escala passam, também, a constituir-se como meio viabilizador de um modelo de gestão das políticas públicas identificado como Estado Avaliador (AFONSO, 1999). Este modelo, inspirado em princípios gerencialistas, pressupõe, entre outros aspectos, que os resultados obtidos pelos alunos nas provas sejam considerados como evidências da qualidade das escolas, e que as mesmas sejam responsabilizadas pelos resultados aferidos. Desse pressuposto decorrem duas consequências: a homogeneização do que se ensina nas escolas, uma vez que serão comparadas; e o estreitamento da noção de currículo e do papel social da escola básica, pois o que será cobrado nas provas passa a balizar as escolhas do que será ensinado. Além disso, a avaliação em larga escala "passou a se constituir em um instrumento de controle do trabalho escolar e de fortalecimento da meritocracia, noção que historicamente, de modo dominante, está subjacente ao trabalho escolar" (SOUSA, 2014, p.413).

Praticamente todos os estados brasileiros já criaram seus próprios sistemas de avaliação. No estado de São Paulo, o SARESP, implantado em 1996, propõe-se a "produzir um diagnóstico da situação da escolaridade básica paulista, visando orientar os gestores do ensino no monitoramento das políticas voltadas para a melhoria da qualidade educacional” (SÃO PAULO, 2014).

O SARESP avalia os alunos do $2^{\circ}, 3^{\circ}, 5^{\circ}, 7^{\circ}$ e $9^{\circ}$ anos do Ensino Fundamental (EF), e da $3^{a}$ série do Ensino Médio (EM) com questões de Língua Portuguesa, Matemática, Ciências Humanas, Ciências da Natureza e Redação. As disciplinas de Língua Portuguesa e Matemática são avaliadas anualmente, enquanto as disciplinas de Ciências, Física, Química e Biologia (Ciências da Natureza) e História e Geografia (Ciências Humanas) são avaliadas anualmente, mas de forma alternada. Não são avaliadas as disciplinas de Artes, Educação Física, Língua Estrangeira, Filosofia e Sociologia.

A verificação do desempenho dos alunos da Educação Básica, de acordo com o documento de implantação, está atrelada à formação dos professores, reorientação da proposta pedagógica das escolas a fim de ajustá-la às expectativas de aprendizagem, planejamento escolar e estabelecimento de metas para o projeto de cada escola (SÃO PAULO, 1996).

De acordo com Bonamino e Sousa (2012, p. 380),

Práxis Educativa, Ponta Grossa, p. 657-675, v. 11, n. 3, set./dez. 2016 Disponível em: <http://www.revistas2.uepg.br/index.php/praxiseducativa > 
Os sentidos do SARESP para professores e alunos da rede pública estadual paulista...

[...] associando a avaliação à melhoria da qualidade do ensino, o documento de implantação revela que tal qualidade é dependente, por um lado, do compromisso dos gestores do sistema de ensino e, por outro, das escolas, sendo estas particularmente responsabilizadas pelo desempenho dos alunos.

No estado de São Paulo, desde 2001, a preocupação com o desempenho vincula os resultados aferidos ao Bônus Mérito $^{2}$.A partir de 2008, os resultados do SARESP, junto com os dados de fluxo das escolas, passaram a compor o Índice de Desenvolvimento da Educação do Estado de São Paulo (IDESP). A partir de então, a Secretaria de Educação do Estado de São Paulo (SEESP) estabeleceu metas anuais a serem atingidas por cada escola estadual. Quando a meta não é atingida pela escola, os professores e demais funcionários não recebem o Bônus Mérito. Desse modo, o SARESP atende a um modelo de política de responsabilização que envolve consequências diretas para diretores, professores e demais funcionários da escola.

Somado a isso, a partir de 2007, o SARESP ganhou uma importância ainda maior, porque passou a ser o termômetro principal para a implantação do plano de metas da Secretaria de Educação do Estado de São Paulo (SÃO PAULO, 2007), acompanhando a escala do Sistema de Avaliação da Educação Básica (SAEB). Decorrente destas reformulações, emergiu a possibilidade de comparação entre os resultados de ambas as avaliações, devido à escala do SARESP apresentar-se congruente aos parâmetros e critérios definidos na avaliação nacional do SAEB (SANTOS; SABIÁ, 2014).

Bonamino e Sousa (2012) destacam que, embora o SARESP se proponha a subsidiar a as discussões sobre o currículo escolar e a qualidade de ensino, produzindo informações de modo a direcionar recursos técnicos e financeiros, e definindo a implantação de ações pedagógicas e administrativas, muitas das consequências acabam sendo negativas.

Esse modelo de avaliação não pode evitar as contradições entre seus motivos de implantação e seus efeitos, suas consequências. Ao mesmo tempo em que a mensuração do desempenho dos alunos, recorrendo aos mesmos parâmetros curriculares pode provocar a equidade de oportunidades e uma discussão mais informada sobre o currículo escolar, o uso de provas padronizadas promove o "[...] alinhamento, nas escolas e secretarias de educação, entre o currículo ensinado e o currículo avaliado" (BONAMINO; SOUSA, 2012, p. 386). Isso fica mais evidente, segundo as autoras, quando se percebe a correspondência entre o currículo oficial, as matrizes do SARESP e os materiais didáticos disponibilizados para professores e alunos (Cadernos do Professor e Cadernos do Aluno ${ }^{3}$ ).

Nesse sentido, Santos e Sabiá (2015), com base em resultados de pesquisas realizadas em nível de mestrado e doutorado, afirmam que o SARESP tem causado diversas consequências para o trabalho pedagógico:

\footnotetext{
2 Instituído pela Lei Complementar no 909 de 2001 e reformulado em 2005 (Lei Complementar no 984 ) e 2008 (Lei Complementar $n^{\circ}$ 1078), o Bônus Mérito é um valor pago aos professores e demais profissionais das escolas, uma vez ao ano, sem que seja incorporado aos salários dos professores. $O$ valor pago baseia-se na frequência dos professores às aulas; relação da escola com a comunidade; realização de projetos; resultados do Índice de Desenvolvimento da Educação do Estado de São Paulo (IDESP) com base no desempenho dos alunos nas avaliações externas, taxas de aprovação, evasão e repetência escolar; bem como nas metas estabelecidas pela Secretaria de Estado da Educação de São Paulo para cada escola estadual (BARBOSA; FERNANDES, 2013).

${ }^{3}$ No bojo do programa intitulado São Paulo Faz Escola é instituído, na rede pública educacional paulista em 2010 , um novo currículo oficial, que é organizado na forma de materiais didáticos identificados como Caderno do Professor e Caderno do Aluno, que são enviados às escolas para serem utilizados nas aulas.
}

Práxis Educativa, Ponta Grossa, p. 657-675, v. 11, n. 3, set./dez. 2016 Disponível em: <http://www.revistas2.uepg.br/index.php/praxiseducativa> 
[...] utilização do Saresp como critério de aprovação (ou não) em final de ciclo escolar; utilização como modelo para a elaboração de novas provas; realização de treinamento dos alunos por parte dos professores para realizarem a avaliação; avaliação externa sendo utilizada como avaliação da aprendizagem; direcionamento e controle do trabalho docente; comercialização de notas; foco estritamente nos componentes curriculares; currículo prescrito; regulação do trabalho docente; e limitação da autonomia do professor em sala de aula. (SANTOS; SABIÁ, 2015, p. 380).

Sordi e Lüdke (2009) chamam a atenção para o fato de que, sem avaliação, não há evidências que permitam monitorar e interferir em condições que possam prejudicar, ou mesmo potencializar a obtenção dos objetivos educacionais pretendidos. No entanto, conforme assinalado por Bonamino e Sousa (2012), o uso de testes padronizados só permite aferir objetivos relacionados ao aspecto cognitivo. Partindo do pressuposto que os currículos escolares possuem múltiplos objetivos, a interpretação dos resultados com base nesse aspecto limita a compreensão dos muitos outros que a escola deve alcançar.

Associado a esses aspectos, Moreira e Sordi (2004), e também Pinto (2011) destacam que essa preocupação com os resultados da avaliação das escolas reforça o controle sobre a ação do docente, que pode orientar seu trabalho, quase que exclusivamente para solucionar o baixo desempenho dos alunos mediante um padrão de qualidade estabelecido externamente pela gestão dos sistemas de ensino. Segundo os autores, os professores, para atender às metas estabelecidas externamente, tendem a privilegiar os conteúdos a serem avaliados, desconsiderando a proposta da própria escola e seu projeto político-pedagógico (PPP).

No caso do estado de São Paulo, a avaliação associada à política de responsabilização aumenta ainda mais a preocupação de diretores e professores em preparar os alunos para os testes, levando a um estreitamento do currículo escolar. Neste sentido, Arcas (2009, p. 69-70) aponta que "[...] ao mesmo tempo em que se anuncia como elemento de gestão das políticas para a melhoria da qualidade do ensino, também está presente, cada vez mais, seu uso como prestação de contas, premiação e punição".

A pesquisa de Arcas (2010), sobre a influência do SARESP no currículo e no desenvolvimento de estratégias de ensino de uma escola pública, evidenciou que muitos professores orientam suas práticas pedagógicas com base nesse exame:

[...] levam as provas do Saresp para a sala de aula, aplicam os exercícios, elaboram atividades seguindo esse modelo, corrigem e analisam as redações, utilizando a estrutura de análise e correção proposta, incluem ou eliminam conteúdos do planejamento de ensino e de aulas conforme o que "cai" no Saresp. (ARCAS, 2010, p. 485, grifos do autor).

Valorizando excessivamente os resultados, as instituições de ensino podem abrir mão de propostas curriculares inovadoras e que se proponham a ir além do currículo oficial, em função de atividades que preparem melhor para o teste. Desse modo, as escolas podem estar submetendo-se e adequando-se à prática avaliativa externa e, como consequência, trabalhando a partir de um ensino fragmentado, superficial e reprodutivo.

Tudo leva a crer que, com a intensificação da importância das avaliações para o norteamento de políticas educacionais, o trabalho docente vai sendo alterado, na medida em que o currículo deixa de ser discutido coletivamente pelos professores da escola com vistas a atender às necessidades e interesses dos alunos, e passa a ser ajustado para melhorar o desempenho nas avaliações. Dessa

Práxis Educativa, Ponta Grossa, p. 657-675, v. 11, n. 3, set./dez. 2016 Disponível em: <http://www.revistas2.uepg.br/index.php/praxiseducativa> 
forma, a discussão sobre o PPP da escola é secundarizada em função da urgência de se atender ao que é cobrado pelas avaliações externas (CUNHA; BARBOSA; FERNANDES, 2015).

Diante desse cenário, quais sentidos professores e alunos conferem ao SARESP e quais são os desdobramentos para a gestão do currículo na sala de aula?

\section{O trabalho de campo}

A escola onde a pesquisa foi realizada atende alunos do Ensino Fundamental II e Ensino Médio, e está localizada em um bairro distante $6 \mathrm{~km}$ do Centro de uma cidade do interior paulista. Atende aproximadamente 900 alunos divididos em três períodos, e conta com cerca de 40 professores. Segundo caracterização do PPP, a escola está inserida em uma comunidade bastante carente, e muitos moradores e pais de alunos não têm uma profissão definida, o que os obriga a trabalhar em vários serviços temporários e informais.

O grupo de pesquisadores frequentou as ATPC quinzenalmente durante o ano de 2014, e mensalmente durante o ano de 2015, participaram das reuniões conduzidas pela equipe da escola (diretora e professores coordenadores) e também coordenaram reuniões com temáticas específicas sobre a avaliação externa e o currículo.

As ATPC contaram, basicamente, com a presença dos professores, mas em algumas delas foram incluídos alunos. Neste artigo discutimos o conteúdo de diferentes ATPC, com ênfase nos encontros que trataram da avaliação, sobretudo a ATPC identificada como Reflexão SARESP, prevista no calendário escolar (agosto de 2014), e as três reuniões que contaram com alunos do $9^{\circ}$ ano do Ensino Fundamental e $3^{\circ}$ ano do Ensino Médio (outubro e novembro de 2014).

Os alunos foram convidados pelos pesquisadores para participarem, com anuência da direção da escola, e o critério de seleção foi serem representantes de classe. O critério justifica-se pelo fato de que, por terem sido eleitos por seus pares, poderiam representá-los, tornando-se porta vozes dos colegas. Dessas reuniões participaram 16 alunos do Ensino Fundamental e 9 alunos do Ensino Médio. Todos eles já tinham experiência com a realização do SARESP em edições anteriores.

Todos os encontros foram audiogravados e transcritos para análise. Além das transcrições também foram considerados os registros escritos elaborados pelos professores por ocasião da Reflexão SARESP. Estes, por sua vez, correspondem à sistematização escrita das preocupações e expectativas dos professores com respeito à aplicação da avaliação externa.

Os procedimentos para a análise das transcrições das ATPC e dos registros escritos envolveram, em um processo de sucessivas leituras, a identificação de indicadores e a seleção de enunciados que indicavam a multiplicidade de sentidos atribuídos pelos professores e alunos sobre o SARESP.

De acordo com Aguiar et al. (2009, p. 65), "falar de sentidos é falar de subjetividade, da dialética afetivo/cognitivo [sic], é falar de um sujeito não diluído, de um sujeito histórico e singular ao mesmo tempo". Os sentidos expressos nos discursos dos professores e alunos, nessa perspectiva, são expressões que informam vivências afetivas e cognitivas imbricadas e convertidas em sentidos.

Práxis Educativa, Ponta Grossa, p. 657-675, v. 11, n. 3, set./dez. 2016 Disponível em: <http://www.revistas2.uepg.br/index.php/praxiseducativa> 
Os sentidos podem ser conhecidos, no campo semântico, a partir de palavras e generalizações que exprimem significados. Os significados, segundo Aguiar e Ozella (2006, p. 226), referem-se "[...] aos conteúdos instituídos, mais fixos, compartilhados, que são apropriados pelos sujeitos, configurados a partir de suas próprias subjetividades".

Isso significa, de acordo com os autores que, para compreendermos as perspectivas dos sujeitos partimos dos significados e, por meio do processo de interpretação e análise, caminhamos para as zonas de sentido que são mais instáveis e fluidas.

O processo de análise, nessa abordagem, exige a aglutinação de indicadores e seus conteúdos, buscando articular núcleos de significação com base nos conteúdos semelhantes, complementares ou divergentes, de modo que se possa evidenciar as possíveis transformações e contradições que ocorrem no processo de construção dos sentidos e dos significados (AGUIAR; OZELLA, 2013).

Importante destacar que "[...] a apreensão dos sentidos não significa apreendermos uma resposta única, coerente, absolutamente definida, completa, mas expressões muitas vezes parciais, prenhes de contradições, muitas vezes não significadas pelo sujeito" (AGUIAR; OZELLA, 2013, p.307), mas que evidenciam indicadores de sua forma de ser e viver.

A leitura sistemática das transcrições das ATCP, da Reflexão SARESP e dos registros escritos pelos professores permite afirmar que não há homogeneidade na forma como os professores e os alunos compreendem as avaliações externas, especificamente o SARESP.

Os diferentes sentidos atribuídos por eles foram agrupados em dois núcleos de significação: o primeiro, O SARESP como parâmetro e referência, contempla as falas de professores e alunos que, mesmo com ressalvas, tendem a admitir que a realização de avaliações externas é importante. $\mathrm{O}$ segundo, O SARESP como medida e controle, reúne as falas de professores que fazem críticas ao SARESP e de alunos que, muitas vezes, não compreendem para que serve essa avaliação.

\section{O SARESP como parâmetro e referência}

Apesar da consistência das críticas às avaliações externas postas pela literatura acadêmica (HORTA NETO, 2010; LIMA, 2011; SOUSA, 2003, 2014; BONAMINO; SOUSA, 2012; FERNANDES, 2013) e destacadas por professores e alunos, muitos deles reconhecem que as avaliações externas são importantes.

Esses professores e alunos partem do princípio de que a avaliação faz parte do processo pedagógico e que pode estabelecer referências para a organização do trabalho do professor na sala de aula. Reconhecem o caráter formativo da avaliação, que deve ter por objetivo "[...] compreender melhor a realidade e, dessa forma, atuar sobre ela, dentro dos limites impostos pelos instrumentos utilizados" (HORTA NETO, 2010, p. 89).

Fernandes (2013) destaca que a avaliação tem estado presente em todas as áreas, e que tem auxiliado em vários aspectos:

A avaliação é um domínio fundamental do conhecimento porque nos permite formular juízos acerca de todas as áreas de funcionamento da sociedade e tomar decisões fundamentadas, tendo em vista a sua melhoria. De forma mais ou menos explícita, mais ou menos formal, a avaliação está efetivamente presente em todos os domínios acadêmicos e

Práxis Educativa, Ponta Grossa, p. 657-675, v. 11, n. 3, set./dez. 2016 Disponível em: <http://www.revistas2.uepg.br/index.php/praxiseducativa> 
Os sentidos do SARESP para professores e alunos da rede pública estadual paulista...

em todas as áreas da atividade humana, podendo garantir a todos e a cada um dos cidadãos que os bens e serviços de que necessitam são de qualidade e não põem em causa os seus legítimos interesses ou mesmo a sua saúde e segurança. (FERNANDES, 2013, p. 12).

Os enunciados abaixo, extraídos dos registros escritos dos professores, revelam a valorização da dimensão formativa, ou seja, uma avaliação voltada para o desenvolvimento dos alunos e "[...] orientada no sentido não de dar notas nem classificar alunos, mas no sentido de determinar quanto eles aprenderam, quais dificuldades e facilidades têm" (GATTI, 2003, p.108).

Penso que são estratégias importantes [avaliações] e devem ser pensadas como parte do processo de aprendizagem (Professor de Lingua Portuguesa).

São de extrema importância, servindo de referência para o desenvolvimento dos trabalhos pedagógicos (Professor de Biologia).

[Sua função é] contribuir com o trabalho pedagógico (de todas as matérias) (Professor de Artes).

Contribui para o trabalho, pois através dos resultados podemos elaborar o planejamento das aulas com o objetivo de trabalhar as dificuldades (Professor do Projeto de Apoio à Aprendizagem - PA $A^{4}$ ).

As respostas dos professores evidenciam que a avaliação é considerada parte do processo pedagógico e parâmetro para a organização do trabalho do professor. Segundo Sordi (2005) a avaliação realmente pode traduzir as potencialidades e dificuldades dos alunos, contribuindo para o ajuste do planejamento e intervenção. Se utilizados com essa finalidade, os resultados da avaliação externa podem apontar elementos para subsidiar o trabalho docente e a aprendizagem discente, proporcionando respaldo para o trabalho pedagógico.

De fato, os objetivos anunciados no documento de implantação do SARESP são:

\begin{abstract}
Verificar o desempenho dos alunos da educação básica para fornecer informações a todas as instâncias do sistema de ensino que subsidiem a capacitação dos recursos humanos do magistério; a reorientação da proposta pedagógica das escolas, de modo a aprimorá-la; a viabilização da articulação dos resultados da avaliação com o planejamento escolar, capacitação e o estabelecimento de metas para o projeto de cada escola. (SÃO PAULO, 1996, p. 7).
\end{abstract}

Outros professores também compreendem que os objetivos do SARESP fazem sentido e contribuem para subsidiar o trabalho da escola de diversas maneiras, como podemos observar nos registros escritos dos professores:

Ajuda a direcionar os trabalhos da escola, pensar e repensar as práticas (Professor de Lingua Portuguesa).

Elas [as avaliações externas] são mais um instrumento norteador do nosso trabalho, à medida que, a partir dessas avaliaçoes, também se pode refletir sobre o nosso trabalho e perceber (mais de uma maneira) as dificuldades dos alunos (Professor de Lingua Portuguesa).

${ }^{4}$ O Projeto Apoio à Aprendizagem (PAA) foi instituído pela Resolução SE 68, de 27/09/2013 e alterado pela Resolução SE 71, de 29/12/2014, com objetivo de atender às demandas pedagógicas relativas às classes dos anos finais do Ensino Fundamental e das séries do Ensino Médio. Os docentes do PAA são ocupantes de função-atividade e têm como atribuições subsidiar as atividades programadas pelos professores das disciplinas do $7^{\circ}, 8^{\circ}$ ou $9^{\circ}$ ano do Ensino Fundamental, e/ou de série do Ensino Médio, e intervir diante das dificuldades específicas dos alunos (SÃO PAULO, 2014).

Práxis Educativa, Ponta Grossa, p. 657-675, v. 11, n. 3, set./dez. 2016 Disponível em: <http://www.revistas2.uepg.br/index.php/praxiseducativa > 
[As avaliações] permitem que os professores discutam, de forma global, o que é preciso melhorar: interpretação de texto, leitura de gráfico (Professor de Matemática).

Avaliar, de maneira geral, é sempre bom, nos faz repensar algumas práticas com os resultados obtidos, discutir novas maneiras de trabalho (Professor de Matemática).

[Oferece] referências para o desenvolvimento do projeto pedagógico (Professor de Biologia).

É importante perceber, a partir dos enunciados, que os professores assumem o SARESP como uma referência para orientar o trabalho da escola, inclusive o projeto pedagógico.

Embora existam diferentes tipos de avaliação, como a avaliação do rendimento escolar, avaliação institucional e avaliação em larga escala, quase sempre ela é concebida como uma atividade que deve orientar o porvir, com vistas a manter ou melhorar a ação futura (GATTI, 2003). Os professores que foram sujeitos dessa pesquisa fazem referência a esses três tipos de avaliação,atribuindo, ao SARESP, a função de identificar as dificuldades dos alunos (avaliação do rendimento)e do trabalho realizado pela escola (avaliação institucional). A questão é que a avaliação externa ou em larga escala, compreendida dessa forma, passa a ser reconhecida como o centro do processo pedagógico, e não parte dele. Ou seja, as falas dos professores, ao mesmo tempo em que resgatam o sentido pedagógico da avaliação externa, evidenciam que ela se tornou a síntese, o norte, a referência principal do trabalho pedagógico da escola.

Esse norte é percebido por alguns professores como direção coletiva, e alguns enunciados abaixo deixam clara essa compreensão:

[É preciso] observar as habilidades não contempladas a fim de sanar os problemas, mas é preciso que TODA a escola 665 esteja efetivamente engajada na causa, e não trabalhar as habilidades apenas em formato de questões de múltipla escolha. O trabalho pode ser feito com leituras, dicionários (manusear), producões textuais com intervencões em todas as disciplinas (Professor de Lingua Portuguesa).

[Devemos] compartilhar responsabilidades, apresentando para todos os professores da escola das disciplinas que não estão envolvidas nas avaliações para que, juntos, possamos encontrar sentido para a aplicaşão (Professor de Matemática).

Penso que as avaliacões externas devem ser trabalbadas em uma perspectiva dialogada com toda a equipe escolar, ou seja, questionando as suas finalidades, os seus conteúdos, permitindo ao professor contribuir com um olhar mais crítico, que possibilite a sua autonomia das avaliações (Professor de Filosofia).

O sentido da avaliação como norte do trabalho coletivo, na concepção desses professores,supõe a partilha de responsabilidades para atender às exigências do SARESP. Isso fica mais claro no enunciado de um professor manifesto em ATPC:

O que eu, filosofia, sociologia, história, educação física, na minha disciplina, ao pegar isso aqui [resultados do SARESP], posso contribuir para o meu colega? Porque não é só português e matemática, nesse ano o SARESP é física, química, biologia e ciências. Mas não é só isso: eu, de inglês, não posso contribuir com nada? A professora de artes não pode contribuir com nada? Pera lá, nós não somos um conjunto? A escola é feita por todos (Professor de Inglês).

Práxis Educativa, Ponta Grossa, p. 657-675, v. 11, n. 3, set./dez. 2016 Disponível em: <http://www.revistas2.uepg.br/index.php/praxiseducativa> 
Os sentidos do SARESP para professores e alunos da rede pública estadual paulista...

A preocupação com o trabalho coletivo e com a colaboração, neste sentido, está orientada para o atendimento dos resultados e metas. O princípio de que a escola é feita por todos não aparece associado a uma ação coletiva voltada à integração das disciplinas e significatividade dos conteúdos, mas ao cumprimento das matrizes de referência do SARESP.

Os alunos, por sua vez, embora aparentemente não demonstrem muita clareza sobre a função do SARESP, admitindo não saberem para que serve, demonstram perceber a dimensão de controle da avaliação, mas associam-na a um aspecto positivo.Parecem acreditar que se trata de uma forma de o governo avaliar o ensino nas escolas, verificando se o professor está ensinando o conteúdo necessário. De algum modo demonstram incorporar o discurso de responsabilização sobre os professores.

Eu acho que é porque o resultado vai mostrar o quanto os professores estão ensinando para os alunos (aluno do $9^{\circ}$ ano EF).

Não vai julgar a gente, só a escola. É o pensamento que fica na cabeça de alguns (aluno do $9^{\circ}$ ano EF).

Apesar da pressuposição feita pelos alunos do $9^{\circ}$ ano do Ensino Fundamental, de que o foco da responsabilidade por atingir bons resultados no processo de aprendizagem esteja no professor, os alunos do $3^{\circ}$ ano do Ensino Médio demonstram chamar para si a responsabilidade pelos resultados:

Acho que é uma maneira de o aluno ver como está se desenvolvendo através da prova também (aluno do $3^{\circ}$ ano EM).

Em minha opinião, eu sempre quis a minha escola lá na frente [no ranking da Diretoria de Ensino], nunca falo mal da minha escola. Ah, todo mundo que eu ouço falar "a escola $X$, a escola $X$ mudou"... Quem faz a escola são os alunos, não os professores. Os professores dão o máximo deles, se os alunos não querem aprender, eles não podem fažer mais nada (aluno do $3^{\circ}$ ano EM).

Tanto os alunos do $9^{\circ}$ ano EF quanto os do $3^{\circ}$ ano EM compreendem que a avaliação funciona como um monitoramento, em alguns casos sobre o ensino, em outros, na aprendizagem. De qualquer modo, veem isso como algo positivo, muito embora não tenham clareza de que o discurso de responsabilização sobre o professor ou sobre o próprio aluno não leva em conta as condições de trabalho dos professores e de vida dos estudantes.

\section{O SARESP como medida e controle}

Diferentemente dos professores que associam a avaliação externa às oportunidades de reflexão, ajuste no planejamento e intervenção no processo de ensino e aprendizagem, há profissionais que não reconhecem as contribuições do SARESP e tecem críticas ao fato de a prova não respeitar a particularidade de cada escola e a realidade dos alunos.

Esses professores partem do princípio de que não se pode aplicar a mesma medida de avaliação a escolas que vivem realidades e experiências distintas. Para Rodrigues (2011), a avaliação por resultados desconsidera justamente as diversidades de contexto das escolas, e se equivoca ao adotar uma prática avaliativa homogeneizadora.

As críticas relacionadas abaixo destacam esses aspectos:

Práxis Educativa, Ponta Grossa, p. 657-675, v. 11, n. 3, set./dez. 2016 Disponível em: < http://www.revistas2.uepg.br/index.php/praxiseducativa > 
São falhas [as avaliações] à medida que não respeitam as individualidades, o trabalho realizado por cada escola, já que cada uma tem um público alvo distinto e a política educacional pede que se tenha um olhar especial para [a] realidade de cada escola (Professor de Lingua Portuguesa).

Tem alcance limitado, pois, apesar de todas as escolas pertencerem a um mesmo sistema, cada uma, em função da atual conjuntura social, possui uma realidade muito própria e específica (Professor de Física).

Observo falbas no sentido de tentar homogeneizar as salas, aplica-se uma única avaliação para todas as escolas, desrespeitando, assim, a individualidade, o trabalho e inclusive a cultura local, uma vez que é sempre dito que precisamos ter um olhar diferenciado para nossos alunos, valorizando sua cultura (Professor de Matemática).

Esses professores chegam a questionar a validade da avaliação externa, uma vez que entendem que, por não estarem adequadas ao contexto da escola, inclusive por serem elaboradas por pessoas alheias a essa realidade, não podem refletir corretamente seus resultados:

É bem relativo afirmar que o SARESP pode contribuir com o trabalbo, porque ele não pode ser considerado um indice verdadeiro sobre o nivel de aprendizagem dos alunos, tanto da maneira como se apresenta a prova, como a maneira que os alunos a realizam (Professor de Geografia).

Não vejo nenhum [sentido], pois é uma avaliação elaborada por pessoas de fora da escola (Professor de Educação Física).

As avaliações em larga escala parecem enfrentar esses limite e contradições: precisam de um padrão, uma medida para orientar as políticas educacionais, mas desrespeitam a diversidade do trabalho desenvolvido por diferentes escolas; destacam a importância do projeto pedagógico que singularize a escola, mas exigem o cumprimento do currículo oficial que normatiza e padroniza o que vai ser ensinado.

De acordo com Rosistolato e Viana (2014, p. 13), os sistemas de avaliação de ensino "[...] foram concebidos com base em um modelo de escola que pressupõe a homogeneização da distribuição do saber escolar". Esse modelo corresponde ao esforço da SEESP, portanto, de unificar o currículo e, consequentemente, eliminar a diversidade. Parte-se do pressuposto de que a padronização do currículo é necessária ao sistema de avaliação; no entanto, conforme pesquisa de Arcas (2010), mesmo com um currículo unificado não se pode desprezar o contexto em que cada escola se encontra inserida.

Outras críticas dos professores incidem sobre uma suposta incompatibilidade entre o modelo de avaliação e as exigências do SARESP e o que, de fato, é trabalhado na escola.

O problema se estabelece quando ocorre um descompasso entre o trabalho efetivamente realizado em sala de aula e 0 que é exigido nas provas (Professor de História).

[O resultado da avaliação externa] fornece uma visão parcial e fragmentada do aprendizado [...], muitas vežes o conteúdo da avaliação não combina com o conteúdo trabalhado pela escola (Professor de Educação Física).

Tinham que levar em consideração as diferentes realidades de nossos alunos. Não acho coerente com a nossa realidade (Professor de Química).

Os professores percebem que a aparência de legitimidade das avaliações externas desconsidera as desigualdades sociais e as condições de trabalho de cada escola. Além disso, o grau

Práxis Educativa, Ponta Grossa, p. 657-675, v. 11, n. 3, set./dez. 2016 Disponível em: <http://www.revistas2.uepg.br/index.php/praxiseducativa > 
Os sentidos do SARESP para professores e alunos da rede pública estadual paulista...

de exterioridade do SARESP, em alguns casos, diminui o sentimento de implicação na aplicação e realização da prova.

$\mathrm{Na}$ reunião em que se fazia a Reflexão $S A R E S P$, os professores confrontaram essa prova com a avaliação interna praticada pela escola, chamada de Provão, que não deixa de ser um simulado para o SARESP. Nesse sentido, destacam que, diante dessa avaliação, elaborada pelos próprios professores, os alunos se empenham mais e, inclusive, anseiam pela correção, demonstrando interesse pelos resultados, diferentemente da relação que eles demonstram estabelecer com o SARESP.

Eu percebi, pelo menos na minha disciplina, que eles [os alunos], com o Provão na mão, estavam esperando ansiosos para que você repasse [sic] as questões, corrigisse. Pela primeira vez. percebi isso. Antes eu falava assim: "- Cadê o provão, gente?" E meia dúzia estava com o provão na mão. E dessa vez não, noventa por cento estava lá, esperando: "- Professor você não vai corrigir as questões?". Eu acho que eles fizeram um pouquinho mais, levaram mais a sério (Professor de Lingua Portuguesa).

Inclusive, o $2^{\circ} \mathrm{B}$ e $03^{\circ} \mathrm{A}$ foram as duas salas que pediram um tempo a mais. Já era $11 \mathrm{~h} 30$ e a gente tinha metade da sala ainda fazendo a prova. E falaram: "- Professor, a gente precisa de um pouco mais, a gente não vai conseguir terminar isso". Teve aluno que saiu daqui 12b15. Isso para mim foi um negócio inédito, em todos esses anos que a gente tem o Provão. Então, você vê, de fažer, essa seriedade, realmente ler e resolver (Professor de Matemática).

Eu acho que,pelo fato também da gente estar mais dentro da realidade deles, eles tiveram uma condicãa melhor para fazer essa prova. Eles falaram assim: "- Nossa, isso aqui eu aprendi". "Olha, professor, errei de bobeira". Percebia-se que ele sabia (Professor de História).

Como podemos observar, na discussão dos professores, a avaliação interna, por fazer parte do processo de ensino elaborado no contexto da escola, acaba tendo aceitação positiva por parte dos estudantes. Também possibilita que o professor trabalhe melhor com esta avaliação, o que não é possível no SARESP, devido à falta de retorno, que chega a ser uma questão que preocupa o grupo.

Eu acho, gente, que uma coisa muito simples que poderia ser modificada nesse SARESP é devolver as provas, se as provas ficassem na escola ... (Professor de Lingua Portuguesa).

Alguns professores entendem que os alunos não fazem a prova com seriedade:

É necessário [avaliar], mas,como não tem retorno aos alunos, eles não fazem com seriedade [...]. Não dá para pensar essas avaliações como parâmetros, para definir o nivel de aprendizagem, uma vez que [o SARESP] não é levado a sério por parte dos alunos (Professor de Matemática).

Os professores justificam o pouco empenho dos alunos na realização da prova, o que distorce os resultados da avaliação - Não dá para pensar essas avaliações como parâmetros, para definir o nivel e aprendizagem, uma vez que [o SARESP] não é levado a sério pelos alunos -, pela ausência da dimensão formativa da avaliação que pressupõe, justamente, interpretar os resultados para planejar as intervenções.

As falas dos alunos permitem inferir que eles não têm clareza a respeito do que, exatamente, o SARESP avalia - o aluno ou o professor - porque talvez não percebam a articulação entre esses atores e, tampouco, o que significa avaliar a escola.

Práxis Educativa, Ponta Grossa, p. 657-675, v. 11, n. 3, set./dez. 2016 Disponível em: <http://www.revistas2.uepg.br/index.php/praxiseducativa > 
O enunciado de um dos alunos do $3^{\circ}$ ano do EM demonstra a dificuldade de compreender como o índice da escola é gerado pela SEESP, e a responsabilidade de cada um nesse processo.

Quando eu estava na oitava série nós passamos a meta, e o terceiro ano foi abaixo. Eles não consideraram a nossa nota, eles pegaram a do terceiro e falaram que foi ruim. Acho que eles nem deram importancia para a nota da oitava série, por que passou o indice e continuou [a escola] lá em baixo (aluno do $3^{\circ}$ ano EM).

Além de não compreenderem bem a função da avaliação, os alunos manifestam um estranhamento com relação ao SARESP frente ao que estão acostumados a praticar na escola. Evidencia, assim que, para eles, conforme apontado pelos professores mencionados anteriormente, essa forma de avaliar também está distante da realidade da escola. Nesse sentido, alguns alunos demonstram não estar acostumados com o cartão de respostas; o tempo da prova, que é mais longo; os textos utilizados que, além de extensos, possuem palavras que não fazem parte do vocabulário deles.

Concordando com seus professores, para os alunos, a prova externa não é suficiente para avaliá-los e enfatizam que o professor, por acompanhar o rendimento do aluno o ano inteiro, seria a pessoa ideal para fazer tal julgamento.

Acho que o professor é que tem mais conbecimento, ele que conbece o aluno, que conviveu com ele o ano inteiro, que sabe do desempenho do aluno (aluno do $3^{a}$ ano EM).

De modo geral, os alunos afirmam que os resultados do SARESP não traduzem o trabalho realizado na escola.O fator principal que causaria essa distorção seria, na visão dos alunos, a pressão a que são submetidos no ano em que realizam a prova. Relatam que são informados no começo do ano sobre a futura realização da prova, e sofrem a pressão do diretor, do professor coordenador e, principalmente, dos professores durante todo o decorrer do ano.Essa pressão parece ocasionar uma ideia de que essa prova seriaalgo impossível de se resolver.

Desde o primeiro instante na salafica 'esse ano tem SARESP', então é meio uma pressão porque, querendo ou não, a reputação da escola está em nossas mãos, se a gente não fižer isso direito, nossa escola vai para o buraco (aluno do $9^{\circ}$ ano EF).

É o nervosismo que torna difícil (aluno do $9^{\circ}$ ano EF).

As pessoas já julgam achando que é difícil, nem leem (aluno do $3^{a}$ ano do EM).

Acho que, assim, os alunos ficam com medo de fazer o SARESP. Porque há um tempo nós fizemos um simulado que foi o SARESP do ano anterior. A sala inteira tinha vinte perguntas de matemática, acertou quinze, dezessete, a sala toda! (aluno do $3^{a}$ ano do EM).

A professora passa alguma coisa que caia parecido no teste, a gente acerta na sala, dai chega no SARESP, a gente não acerta, porque tem a tensão... (aluno do $9^{\circ}$ ano EF).

Os alunos afirmam ter consciência de que os resultados geram um índice que classifica a escola, mas, mesmo assim, existe a falta de comprometimento com a realização da prova, indicando um descrédito dos alunos para com o SARESP. Segundos eles, isso acontece pelo fato de o governo não divulgar os resultados individuais, de não ter nota, dando a eles a impressão de que a realização da prova não tem nenhum desdobramento.

Práxis Educativa, Ponta Grossa, p. 657-675, v. 11, n. 3, set./dez. 2016 Disponível em: < http://www.revistas2.uepg.br/index.php/praxiseducativa > 
Os sentidos do SARESP para professores e alunos da rede pública estadual paulista...

Ah, acho que é por causa disso mesmo: não tem nota e, também, não vai ajudar nada no bimestre, então eles faz̧em de qualquer jeito, porque é para o governo (aluno do $9^{\circ}$ ano EF).

Eu acho assim, desde sempre o aluno é acostumado com essa coisa, vale nota, faço; não vale, então, por que é que eu tenho que fazer? (aluno do $9^{\circ}$ ano EF).

São somente alguns que se importam com isso também. São só alguns que vão lá e fazerm direito (aluno do $3^{a}$ ano do EM).

Sordi e Lüdke (2009) também lembram que os estudantes, habituados a essas práticas, expropriados do processo de reflexão sobre a avaliação, acostumam-se a juízos de valor externos e, portanto, não contestam uma lógica que os priva da participação em um processo no qual precisariam desenvolver, ao menos, ações de corresponsabilidade.

\begin{abstract}
Esta forma de entender a avaliação e se acostumar com a sua feição classificatória e de vê-la como um ato de comunicação com ares de neutralidade, no qual alguém assume a prerrogativa de dizer o quanto vale o trabalho do outro, sem que a este outro seja dada a oportunidade de se manifestar sobre o processo vivido e suas eventuais idiossincrasias, acaba por esvair desta prática o seu sentido formativo. (SORDI; LÜDKE, 2009, p. 314).
\end{abstract}

\title{
Considerações finais: desdobramentos do SARESP sobre a gestão do currículo em sala de aula
}

Ao tentar compreender os sentidos que professores e alunos atribuem ao SARESP, também foi possível perceber como esse modelo de avaliação tem influenciado a organização do trabalho pedagógico na sala de aula e, sobretudo, o currículo escolar.

Os relatos dos docentes, nas ATPC e nos registros escritos,mencionam a necessidade de correrem com o conteúdo que será cobrado na avaliação, indicando a estreita relação entre o currículo oficial do Estado e o SARESP.

Como tudo parece estar vinculado a essas avaliações, muito trabalho que poderia ser bem direcionado, aprofundado, não é possivel de ser realizado, pois é preciso acelerar o conteúdo da apostila (Professor de Lingua Portuguesa).

Existe uma necessidade de retomada constante de conteúdos, o tempo da aula parece que é insuficiente para que todo o conteúdo da apostila seja contemplado. Parece que estamos condicionados a uma Pedagogia do Exame, o que importa realmente é "treinar" os alunos para que tenham bom desempenho nas avaliações, o que não deve ser o real objetivo (Professor de Matemática).

Os professores demonstram a compreensão de que o currículo é muito mais do que o ensino dos conteúdos que serão cobrados na avaliação. Indicam que a avaliação sobre o currículo deveria, portanto, articular os diversos aspectos constitutivos da educação - sentidos e valores da cognição, autonomia moral, participação na vida social e pública, etc. (DIAS SOBRINHO, 2008).

De acordo com Roldão (1999, p. 16), currículo é “[...] o conjunto de aprendizagens que, por se considerarem socialmente necessárias num dado tempo e contexto, cabe à escola garantir e organizar". Esse conjunto de aprendizagens inclui os conhecimentos das disciplinas, mas vai além deles.

Práxis Educativa, Ponta Grossa, p. 657-675, v. 11, n. 3, set./dez. 2016 Disponível em: <http://www.revistas2.uepg.br/index.php/praxiseducativa> 
Ocorre que a gestão do currículo, ou seja, a decisão "[...] do que ensinar e porquê, como, quando, com que prioridades, com que meios, com que organização, com que resultados" (ROLDÃO, 1999, p. 18) está cada vez mais distante da escola e dos professores.

Pode-se perceber que os professores demonstram sentirem-se sobrecarregados com as exigências para atingirem resultados positivos na avaliação. As expressões tudo parece estar vinculado a essas avaliações, estamos condicionados a uma Pedagogia do Exame, treinar o aluno, evidenciam análises críticas e interferências negativas da avaliação.

Enfrentam um cotidiano em que o domínio de habilidades, competências e conteúdos é considerado mais importante do que a capacidade de tecer explicações e pensar alternativas para os problemas que se colocam na vida dos alunos. Merece destaque a percepção da professora de Matemática, que associa o ensino ao treino de como ir bem na prova.

Para melhorar o desempenho do aluno tenho que mudar a estratégia da aula, ou seja, preciso ensinar o aluno como ir bem na prova, isso não significa que ele absorveu o conteúdo (Professora de Matemática).

Alguns professores afirmaram que os dados obtidos através da avaliação estão moldando o que é trabalhado em sala de aula:

O trabalho de minha disciplina é afetado de forma significativa. O trabalho totalmente voltado para a realidade do meu aluno sofre uma diminuição. Parte do foco é voltada para a avaliação [externa], de tal forma que os alunos não focam no que realmente é necessário (Professor de Física).

De forma semelhante, Santos e Sabiá (2015) destacam que o SARESP tem se configurado como um elemento de controle do trabalho do professor em sala de aula, chegando a inviabilizar o cumprimento da função social da escola:

[...] consideramos que o Saresp na atualidade se constitui um forte dispositivo de controle do trabalho docente em sala de aula, direcionando o que e como ensinar aquilo que posteriormente será avaliado externamente. Esse direcionamento do trabalho docente acaba por inviabilizar a avaliação com função diagnóstica, como processo que busca a valorização do aluno e da sua efetiva aprendizagem, inviabilizando também o cumprimento da função social da escola. (SANTOS; SABIÁ, 2015, p. 381).

É fato que a função do currículo na escola é ampliar as experiências dos alunos para além de seu cotidiano, e que as disciplinas têm um papel central no desenvolvimento dos estudantes (YOUNG, 2011). No entanto, os professores percebem que um currículo voltado para o conhecimento e para as disciplinas não pode estar apartado da vida do aluno, pois é necessário considerar as experiências e os conhecimentos anteriores, que os alunos trazem para a escola, para pensar o mundo.

Estamos diante, como apontado por Young (2011), do conflito entre um currículo baseado no cumprimento - ensinar para o SARESP - e um currículo baseado no engajamento - ensinar para contribuir com o desenvolvimento intelectual dos estudantes.

De acordo com o autor, os conteúdos desempenham três papeis em um currículo de engajamento: oportunizam, aos alunos, o acesso aos conhecimentos produzidos em campos particulares do conhecimento (dimensão curricular); permitem a construção de relações entre os conceitos cotidianos e os conceitos teóricos das diferentes disciplinas (dimensão pedagógica); e

Práxis Educativa, Ponta Grossa, p. 657-675, v. 11, n. 3, set./dez. 2016 Disponível em: <http://www.revistas2.uepg.br/index.php/praxiseducativa> 
Os sentidos do SARESP para professores e alunos da rede pública estadual paulista...

oferecem, aos professores, o sentido de seu trabalho e da sua profissão (dimensão geradora de identidades).

As dimensões curriculares, pedagógicas e de geração de identidades, em alguns casos, ficam ameaçadas, como se pode observar nos registros de dois professores de Filosofia:

Devido aos maus resultados obtidos, minha disciplina é afetada pela bisteria vivida no ambiente escolar, na busca por melhores resultados, colocando, no caso a filosofia, a servico da lingua portuguesa, em atividades de avaliacãa (Professor de Filosofia).

Em minha opinião, as avaliacões externas afetam a autonomia. Vejo que está implícito o controle de trabalho docente em sala de aula, valorizando determinados saberes e desvalorizando outros, exemplo (matemática $X$ artes) com uma perspectiva tecnicista (Professor de Filosofia).

Percebe-se aqui, como já evidenciado na literatura sobre a temática, que a avaliação tem alterado a gestão do currículo, e que as escolas têm cedido para ensinar para os testes. No entanto, o que chama a atenção, nos registros da pesquisa, é que alguns professores demonstram valorizar a avaliação externa, marcando a necessidade de se avaliar e, ainda, marcando o caráter formativo que a avaliação pode ter. Contraditoriamente, também evidenciam que essa avaliação tem se configurado como motor do trabalho pedagógico desenvolvido pela escola, assumindo caráter central no processo educativo.

Parece que o Estado Avaliador mencionado por Afonso (1999), embora pratique um modelo de avaliação muito mais próximo do praticado pelas empresas, com fins de controle mais que qualquer outro, tem dado conta não apenas de impor a centralidade da avaliação, mas convencer sobre a importância dela, resgatando, para isso, um discurso caro aos educadores, que é o da dimensão formativa da avaliação.

Dessa forma, a avaliação externa vai se consolidando e vai redefinindo o currículo, e alterando as práticas nas salas de aula. Não só o que é ensinado muda em função da avaliação, também as formas de avaliar o que é importante. A centralidade da avaliação e a preocupação com os resultados, inclusive, termina por esvaziar a discussão do projeto político-pedagógico, como já apontado por Cunha, Barbosa e Fernandes (2015), uma vez que todo o esforço do trabalho docente está dirigido ao cumprimento das metas estabelecidas.

\section{Referências}

AFONSO, A. J. Estado, mercado, comunidade e avaliação: esboço para uma rearticulação crítica. Educação e Sociedade, Campinas, v. 20, n. 69, p.139-164, dez. 1999. DOI: 10.1590/s010173301999000400007

AGUIAR, W. M. J.; LIEBESNY, B.; MARCHESAN, E. C. SANCHES, S. G. Reflexões sobre sentido e significado. In: BOCK, A. M. B.; GONÇALVES, M. G. M. (Orgs.). A dimensão subjetiva da realidade: uma leitura sócio-histórica. São Paulo: Cortez, 2009. p. 54-72.

Práxis Educativa, Ponta Grossa, p. 657-675, v. 11, n. 3, set./dez. 2016 Disponível em: <http://www.revistas2.uepg.br/index.php/praxiseducativa> 
AGUIAR, W. M. J.; OZELLA, S. Apreensão dos sentidos: aprimorando a proposta dos núcleos de significação. Revista Brasileira de Estudos Pedagógicos, Brasília, v. 94, n. 236, p. 299-322, jan./abr. 2013. DOI: 10.1590/s2176-66812013000100015

AGUIAR, W. M. J.; OZELLA, S. Núcleos de significação como instrumento para a apreensão da constituição dos sentidos. Psicologia, Ciência e Profissão, Brasília, v. 26, n. 2, p. 222-245, jun. 2006. DOI: 10.1590/S1414-98932006000200006

ARCAS, P. H. Saresp e progressão continuada: implicações na avaliação escolar. Estudos em Avaliação Educacional, São Paulo, v. 21, n. 47, p. 473-488, set./dez. 2010.

ARCAS, P. H. Implicações da progressão continuada e do SARESP na avaliação escolar: tensões, dilemas e tendências. 2009, 180f. Tese (Doutorado em Educação) - Universidade de São Paulo, São Paulo, SP, 2009.

BARBOSA, A.; FERNANDES, M. J. F. O pagamento por desempenho no contexto das reformas educacionais paulistas. Comunicações, Piracicaba, v. 20, n. 2, p. 45-59, jul./dez. 2013.

BAUER, A. Avaliação de redes de ensino e gestão educacional: o que apontam os estudos acadêmicos.IV Congresso Ibero-Americano de Política e Administração da Educação; VII Congresso Luso Brasileiro de Política e Administração da Educação. Porto, Portugal, 2014. 16p.Disponível em:<http://www.anpae.org.br/IBERO_AMERICANO_IV/GT2/GT2_Comunicacao/AdrianaBau er_GT2_integral.pdf $\geq$. Acesso em: 15 dez. 2015.

BONAMINO, A.; SOUSA, S. M. Z. L. Três Gerações de avaliação da Educação Básica no Brasil: as interfaces com o Currículo da / na Escola. Educação e Pesquisa, São Paulo, v. 38, n. 2, jun. 2012. DOI: $10.1590 /$ s1517-97022012005000006

CUNHA, R. C. O. B.; BARBOSA, A.; FERNANDES, M. J. S. Implicações das avaliações externas para o trabalho docente coletivo. Estudos em Avaliação Educacional, São Paulo, v. 26, n. 62, p. 386-416, maio/ago. 2015. DOI: 10.18222/eae266203288

DIAS SOBRINHO, J. Avaliação educativa: produção de sentidos com valor de formação. Avaliação, Campinas, v. 13, n. 1, p. 193-207, mar. 2008. DOI: 10.1590/s1414-40772008000100011

FERNANDES, D. Avaliação em educação: uma discussão de algumas questões críticas e desafios a enfrentar nos próximos anos. Ensaio: avaliação e políticas públicas em educação, Rio de Janeiro, v. 21, n. 78, p. 11-34, jan./mar. 2013. DOI: 10.1590/s0104-40362013005000004

GATTI, B. O professor e a avaliação em sala de aula. Estudos em Avaliação Educacional, São Paulo, n. 27, jan./jun. 2003.

HORTA NETO. J. L. Avaliação externa de escolas e sistemas: questões presentes no debate sobre o tema. Revista Brasileira de Estudos Pedagógicos, Brasília, v. 91, n. 227, p. 84-104, jan./abr. 2010. 
LIMA, L. Avaliação, competitividade e hiperburocracia. In: ALVES, M. P.; KETELE, J. M. (Org.). Do currículo à avaliação, da avaliação ao currículo. Porto: Porto, 2011. p. 71-82.

MOREIRA, R. S. M.; SORDI, M. R. L. Avaliação externa como instrumento da gestão do sistema de ensino: a adesão e os impasses para a busca de melhoria na educação. $27^{\mathbf{a}}$ Reunião Anual da Anped, Caxambu, 2004, p. 1-6.

NAMURA, M. R. Por que Vygotski se centra no sentido: uma breve incursão pela história do sentido na Psicologia. Psicologia da Educação, São Paulo, n.19, p. 91-117, ago./dez. 2004.

PINTO, M. A. R. Política pública e avaliação: o SARESP e seus impactos na prática profissional docente. 2011, 170 f. Dissertação (Mestrado em Serviço Social) - Faculdade de Ciências Humanas e Sociais, Universidade Estadual Júlio de Mesquita Filho, Franca, 2011.

RODRIGUES, R. F. Uso e repercussões de resultados do SARESP na opinião de professores da rede estadual paulista. 2011, 112 f. Dissertação (Mestrado em Educação) - Pontifícia Universidade Católica de São Paulo, São Paulo, 2011.

ROLDÃO, M. C. Gestão curricular: fundamentos e práticas. Lisboa: MEC-DEB, 1999.

ROSISTOLATO, R.; VIANA, G. Os Gestores Educacionais e a recepção dos sistemas externos de avaliação no cotidiano escolar. Educação e Pesquisa, São Paulo, v. 40, n. 1, março 2014. DOI: 10.1590/s1517-97022013005000006

SANTOS, U. E.; SABIÁ, C. P. P. Percurso histórico do SARESP e as implicações para o trabalho pedagógico em sala de aula. Estudos em Avaliação Educacional, São Paulo, v. 26, n. 62, p. 354385, maio/ago. 2015. DOI: 10.18222/eae266203006

SANTOS, U. E.; SABIÁ, C. P. P. Percurso histórico do Sistema de Avaliação do Rendimento Escolar de São Paulo - SARESP - e as implicações para o trabalho pedagógico em sala de aula. Anais do III Congresso Nacional de Avaliação em Educação: III CONAVE. Bauru: CECEMCA/UNESP, 2014. p. 1-16.

SÃO PAULO. Secretaria da Educação. Plano de Metas da Educação de São Paulo: uma nova agenda de qualidade da educação. São Paulo, setembro. 2007. Disponível em: $<$ www.educacao.sp.gov.br>. Acesso em: 15 dez. 2015.

SÃO PAULO. Secretaria de Educação. Coordenadoria de Gestão da Educação Básica. Resolução SE 71, de 29-12-2014. Dispõe sobre o Projeto Apoio à Aprendizagem, instituído pela Resolução SE 68, de 27/09/2013. Disponível em: <http://siau.edunet.sp.gov.br/ItemLise/arquivos/71_14.HTM?Time=07/12/2015\%2003:19:40>. Acesso em: 15 dez. 2015.

SÃO PAULO. Secretaria de Estado de Educação. SARESP: documento de implantação. São Paulo: FDE, 1996. 
SORDI, M. R. L. de. Avaliação Universitária: mecanismo de controle, de competição e exclusão ou caminho para construção da autonomia, da cooperação e da inclusão? In: VEIGA, I. P. A.; NAVES, M. L. P. Currículo e Avaliação na Educação Superior. São Paulo: J.M., 2005. p. 121-149.

SORDI, M. R. L. de; LUDKE, M. Da avaliação da aprendizagem à avaliação institucional: aprendizagens necessárias. Avaliação, Campinas, Sorocaba, v. 14, n. 2, jul. 2009. DOI: 10.1590/s1414-40772009000200005

SOUSA, S. M. Z. L. Concepções de qualidade da educação básica forjadas por meio de avaliações em larga escala. Avaliação, Campinas, v. 19, n. 2, p. 407-420, jul. 2014. DOI: 10.1590/s141440772014000200008

SOUSA, S. M. Z. L. Possíveis Impactos das Políticas de avaliação não Currículo escolar. Cadernos de Pesquisa, São Paulo, n. 119, p. 175-190, 2003. DOI: 10.1590/s0100-15742003000200009

YOUNG, M. F. D. O futuro da educação em uma sociedade do conhecimento: a defesa radical de um currículo disciplinar. Cadernos de Educação, Pelotas, n. 38, p. 395-416, jan./abr. 2011.

Recebido em 30/12/2015

Versão corrigida recebida em 10/06/2016

Aceito em 12/06/2016 